\title{
Study on the Problems of Farmers' Property Income Growth from the Perspective of Financial Management
}

\author{
Dehua Zhang ${ }^{1, a^{*}}$ \\ ${ }^{1}$ Harbin University of Commerce, Harbin China 150028 \\ azdh19841027@163.com
}

Keywords: Farmer; Property income; Restricting; Countermeasures

\begin{abstract}
Farmers' income insists of household operations income, wage income, property income and transfer income. National Central Document No.1 states that we should focus on promoting farmers' property income growth in order to increase farmers' income, so studying property income growth has a strong practical significance. The paper starts with the development situation of farmers' property income and comes to the conclusion that farmers' property income keeps fluctuating and rising trend, it is not the main income source and it is far lower than citizens' property income in urban areas. The paper discusses the problems of restricting farmers' property income growth, such as poor continuous increasing on land property, unreasonable land compensation mechanism, lower housing income and weak financial planning basis, then puts forward the following countermeasures and suggestions: promoting the innovation of rural land circulation mode, adjusting the compensation mechanism of land interest, exploring the incentive mechanism of homestead circulation and exit, developing specialized financial products of farmers.
\end{abstract}

\section{Analysis on the Situation of Farmers' Property Income}

Property Income Maintains the Fluctuating and Rising Trend. Property income of national farmers is 7 Yuan in 1993 and is 293 Yuan in 2013. During the 20 years, the income increases by 286 Yuan, an average of 14.3 Yuan each year. On the whole, property income keeps a rising trend. According to the changing situation, it can be divided into the fluctuation stage (1993-1997), the slow rising stage (1998-2002) and the stable rising stage (2003-2013) (see Fig. 1).

In the fluctuation stage (1993-1997), farmers' property income increases first and decreases later. It is 7 Yuan in 1993 and rises to 42.6 Yuan in 1996, then decreases to 23.6 Yuan in 1997. In this stage, the property income repeats again and again, up to 1997, it is only equivalent to the level of 1994.

In the slow rising stage (1998-2002), farmers' property income rises slowly and the rising range reduces gradually. It increases from 30.4 Yuan in 1998 to 50.7 Yuan in 2002, totally rising 20.3 Yuan, an average of 5.08 Yuan each year. In this stage, farmers' property income keeps a rising trend, but the rising range shrinks year by year. This shows that the rising driving force of farmers' property income is weakening gradually.

In the stable rising stage (2003-2013), farmers' property income rises stably and the rising range widens. It increases from 65.8 Yuan in 2003 to 293 Yuan in 2013, totally rising 227.2 Yuan, an average of 22.72 Yuan each year. In this stage, farmers' property income keeps a rising trend for a long time, but the rising range limits relatively and there is no breakthrough growth for 10 years. Up to 2013, property income is 293 Yuan which is less than 5\% of farmers' income.

In conclusion, farmers' property income has an obvious rising trend, but up to 2013, it is 293 Yuan. This can't be comparing with other income which plays a limited role in income growth. 


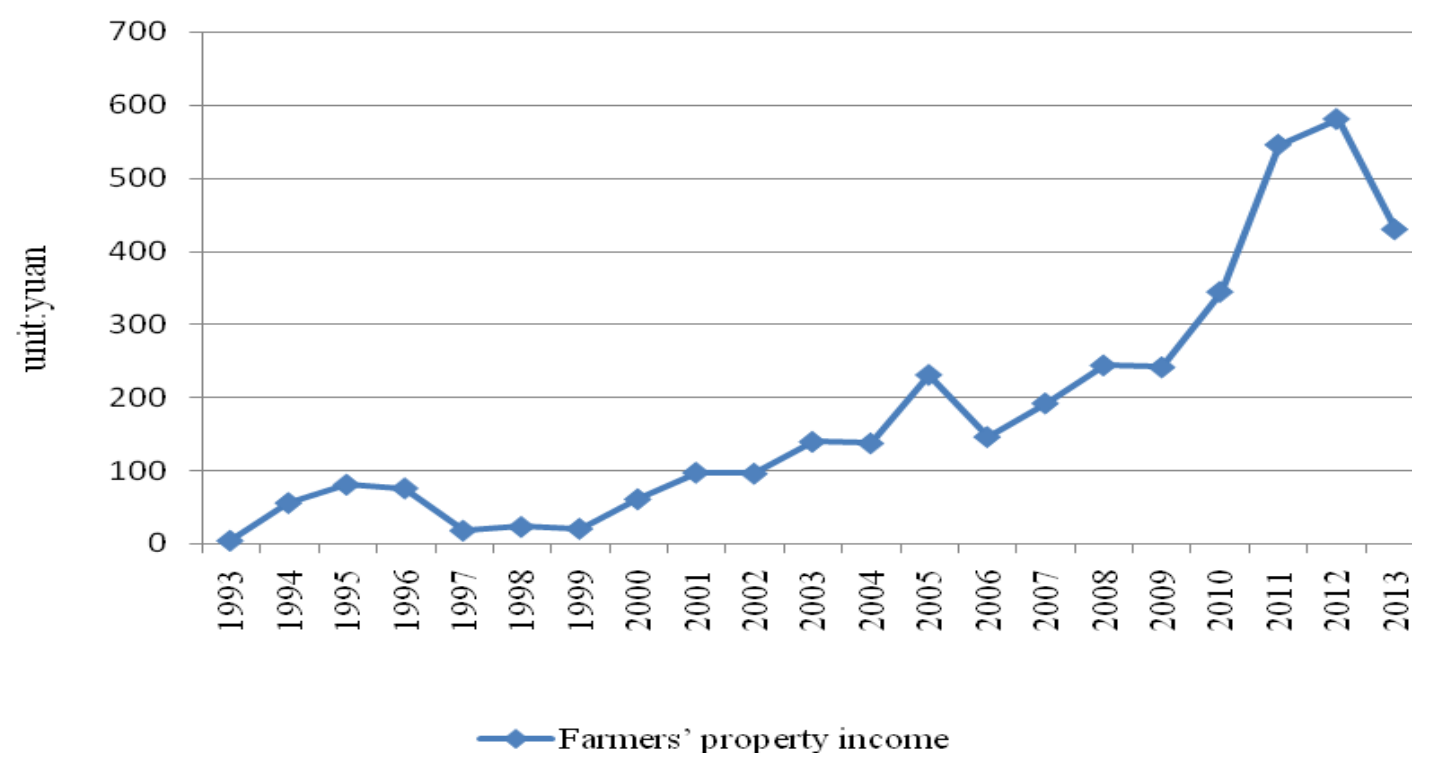

Figure 1. The changing trend of farmers' property income

Farmers' Property Income isn't the Main Income Sources. According to the income sources, farmers' income can be divided into four parts, income from household operations, income from wages and salaries, income from properties and income from transfers. Through comparison, we can see that income from household operations and income from wages and salaries are the main sources of farmers' income, but income from properties is always at the edge.

According to Income Levels, Farmers' Property Income is much lower than the Other Three. In 1993, the property income is 7 Yuan, household operations income is 678.5 Yuan, wage and salary income is 194.5 Yuan and transfer income is 41.6 Yuan. There is a difference of 671.5 Yuan, 187.5 Yuan and 34.6 Yuan respectively between the property income and household operations income, wage and salary income and transfer income. According to the income amount from the highest to the lowest, it is income from household operations, income from wages and salaries, income from transfers and income from properties respectively. Up to 2013, farmers' property income is 293 Yuan, household operations income is 3793.2 Yuan, wage and salary income is 4025.4 Yuan and transfer income is 784.3 Yuan. Through comparison, there is a difference of 3500.2 Yuan, 3732.4 Yuan and 491.3 Yuan respectively between the property income and household operations income, wage and salary income and transfer income. This shows that the gap between the property income and the other three incomes is widening gradually after 20 years development.

According to the Proportion of Farmers' Income, the Property Income is always in a Low Level. In 1993, the proportion of property income is $0.76 \%$ for farmers' income, the proportion of household operation income is $73.62 \%$ for farmers' income, the proportion of wage and salary income is $21.10 \%$ for farmers' income and the proportion of transfer income is $4.51 \%$ for farmers' income. This indicates that farmers' property income is far less than that of three incomes. Up to 2013, the proportion of property income rises to $3.29 \%$ for farmers' income, the proportion of household operation income is $42.64 \%$ for farmers' income, the proportion of wage and salary income is $45.25 \%$ for farmers' income and the proportion of transfer income is $8.82 \%$ for farmers' income (see Fig. 2). After 20 years development, wage and salary income becomes the same important to the household operations income. Although the status of farmers' property income has improved, it doesn't reverse the fundamental trend and it still belongs to the edge of income source. 


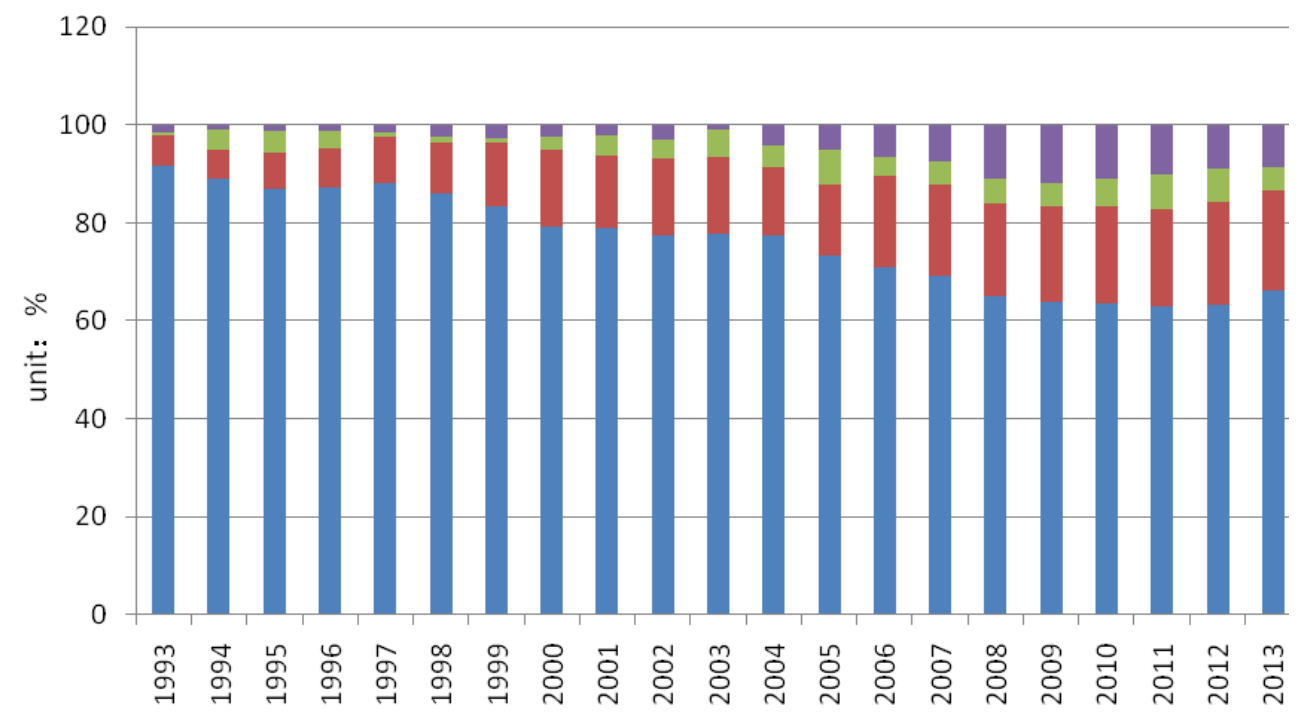

- the proportion of household operation income $\quad$ the proportion of wage and salary income

the proportion of property income $\quad$ the proportion of transfer income

Figure 2. The proportion of farmers' income sources

Table1 Variation tendency of farmers' income sources in Heilongjiang

\begin{tabular}{ccccc}
\hline year & $\begin{array}{c}\text { the proportion } \\
\text { of household } \\
\text { operation } \\
\text { income } \\
(\%)\end{array}$ & $\begin{array}{c}\text { the proportion } \\
\text { of wage and } \\
\text { salary income } \\
(\%)\end{array}$ & $\begin{array}{c}\text { the proportion } \\
\text { of property } \\
\text { income }(\%)\end{array}$ & $\begin{array}{c}\text { the proportion } \\
\text { of transfer } \\
\text { income } \\
(\%)\end{array}$ \\
\hline 1993 & 91.70 & 6.27 & 0.38 & 1.65 \\
1994 & 89.10 & 5.89 & 3.97 & 1.04 \\
1995 & 86.85 & 7.38 & 4.56 & 1.21 \\
1996 & 87.26 & 7.86 & 3.46 & 1.43 \\
1997 & 88.11 & 9.52 & 0.76 & 1.61 \\
1998 & 85.98 & 10.45 & 1.01 & 2.57 \\
1999 & 83.25 & 13.17 & 0.93 & 2.64 \\
2000 & 79.11 & 15.73 & 2.82 & 2.33 \\
2001 & 79.05 & 14.62 & 4.25 & 2.08 \\
2002 & 77.37 & 15.66 & 3.97 & 2.99 \\
2003 & 77.73 & 15.71 & 5.54 & 1.02 \\
2004 & 77.51 & 13.75 & 4.56 & 4.18 \\
2005 & 73.39 & 14.41 & 7.16 & 5.04 \\
2006 & 70.98 & 18.43 & 4.10 & 6.49 \\
2007 & 69.02 & 18.75 & 4.64 & 7.59 \\
2008 & 65.15 & 18.88 & 5.02 & 10.95 \\
2009 & 63.89 & 19.58 & 4.63 & 11.90 \\
2010 & 63.46 & 19.99 & 5.54 & 11.00 \\
2011 & 63.03 & 19.71 & 7.18 & 10.08 \\
2012 & 63.15 & 21.12 & 6.74 & 8.98 \\
2013 & 66.07 & 20.67 & 4.46 & 8.80 \\
\hline
\end{tabular}

Data sources: Calculation based on Heilongjiang Statistical Yearbook

On the whole, considering the income level and the income proportion, the status of farmers' 
property income is still significantly lower than the other three. In essence, farmers' property income plays a limited role in improving income growth. Therefore, farmers' property income has not become the main income source yet.

Farmers' Property Income is Far Lower than Citizens' Property Income. Through comparison, there is a significant gap of property income between farmers and citizens. In 2000, farmers' property income is 45.0 Yuan and citizens' property income is 128.4 Yuan in China, a difference of 83.4 Yuan and citizens' property income is 2.85 times of farmers'. Up to 2013, farmers' property income is 293.0 Yuan and citizens' property income is 809.9 Yuan in China, a difference of516.9 Yuan and citizens' property income is 2.76 times of farmers'.

According to the absolute gap, the minimum gap is 51.4 Yuan in 2002 and the maximum gap is 516.9 Yuan in 2013 during 14 years. It shows that farmers' property income is lower than that of citizens' all the time and the gap between them is widened gradually. According to the ratio of property income, it shows the narrowing trend, but it is extremely limited.

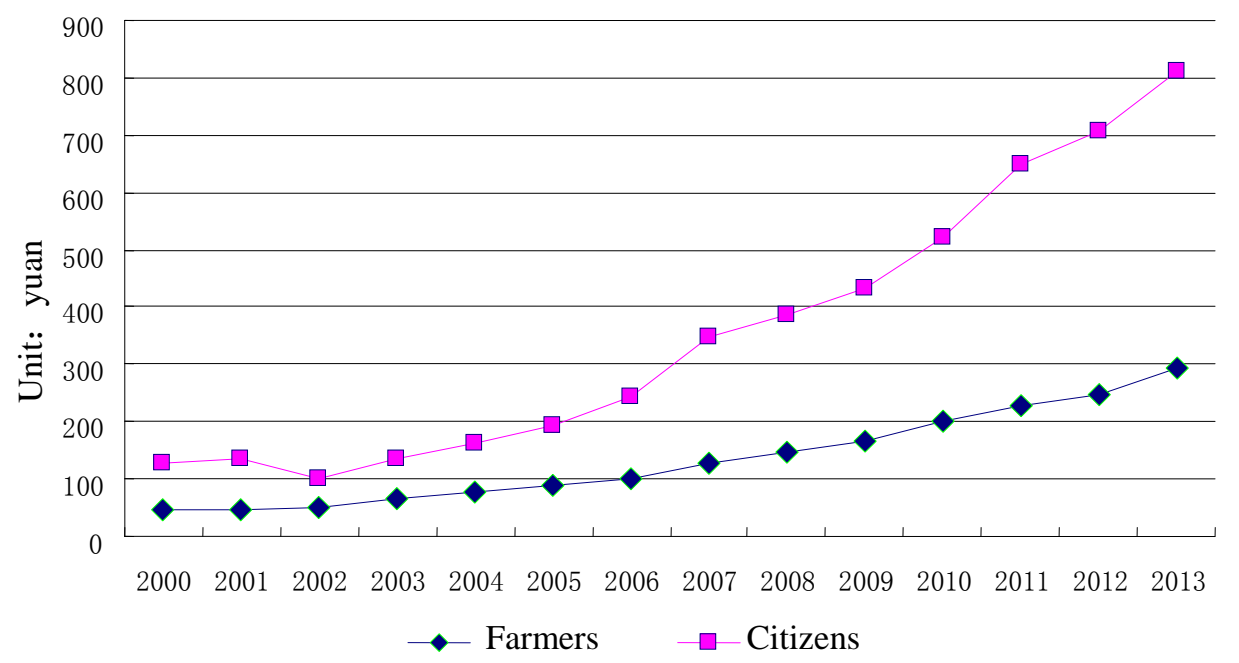

Figure 3. The comparison of property income between farmers and citizens

\section{Analysis on the Problems of Restricting Farmers' Property Income Growth}

Generally speaking, the main sources of farmers' property income include land property income, housing income and financial income ${ }^{[1] .}$ We'll discuss the problems of restricting farmers' property income growth from the above three parts.

Poor Continuous Increasing on Land Property of Farmers. The farmers have no ownership of the land in the land contract period in China. They only have the right to operate, to possess, to use, to dispose and the right to gain benefit ${ }^{[2]}$. For the land property income, most of farmers obtain the rent through the simple land lease and get no land value added benefit.

Unreasonable Land Compensation Mechanism. Generally speaking, the land belongs to the village collective ${ }^{[3]}$. In the process of development and construction of the government, they can collect the rural land for the infrastructure construction. By paying a certain amount of compensation, the government can use the land in rural areas. Our country has adjusted the standard of land compensation many times and improves the compensation for farmers as possible as it can, but the current land compensation standard is still at a low level.

Lower Housing Income of Farmers. Generally speaking, the other income source for farmers' property income is the housing income. When the farmers go out to work, the rural housing is vacant which will cause a certain waste. What's more, the houses in rural areas are far away from the county and the city, the rental prices are very low and fewer people are willing to rent which result in lower housing income for farmers.

Weak Financial Planning Basis of Farmers. It restricts farmers' property income growth. The main performance is as follows: (1) the overall quality of farmers' financial planning is low; (2) the development of financial market is slow in rural areas which restricts farmers' property income growth.

\section{The Countermeasures and Suggestions on Improving Farmers' Property Income Growth}

Promoting the innovation of rural land circulation mode. The enterprises, the cooperatives and the 
farmers actively participate in the land circulation, formulate corresponding land circulation modes and try the mode in the testing areas. The paper focuses on securing the land ownership and discusses the circulation problems of land using rights ${ }^{[4-6]}$.

Adjusting the compensation mechanism of land interest. Through the analysis, we see that the land compensation standard is very unreasonable. So we should adjust the standard of land compensation distribution in order to secure the interests of farmers' land compensation ${ }^{[7]}$.

Exploring the incentive mechanism of homestead circulation and exit. With the progress of urbanization, the rural unused homestead and property can't be effectively applied, so farmers can't get the property income. The paper suggests that the government promotes the circulation of homestead and rural housing through the incentive mechanism of homestead circulation and exit, and promotes farmers 'property income.

Developing specialized financial products of farmers. According to the analysis, lack of financial management knowledge and financial products is the key reason for the low financial property income of farmers ${ }^{[8-10]}$. We should develop financial products for farmers so as to improve farmers' financial property income stably.

\section{Acknowledgment}

The paper is the phase progress of PhD Research Project Started of Harbin University of Commerce (14RW10); this paper is supported by Science Research Foundation of Northeast Agricultural University (item number 2012RCB77); this paper is the phase progress of Philosophy and Social Science Project of Ministry of Education "Research on the Mechanism Innovation of Rural Land Transfer and Its Efficiency \& Income Distribution (item number 14YJC790125)"

\section{References}

[1] Guan Haojie. Analysis on the correlation between the changing of farmers' income structure and income fluctuation in China [J] Journal of Nanjing Audit University, 2013 (3):17-23

[2] Zhong Wenjing, Luo Biliang. Natural endowment effect, property right intensity and farmland transfer suppression -- An Empirical Analysis based on Guangdong Province [J] Issues of Agricultural Economy, 2013(3):6-15

[3] Qian Liangze. Analysis on influential factors and suggestions of farmers' income [J] Macroeconomic Management, 2012(7):37-38

[4] Zhang Dehua, Zhou Huiqiu and Lou Sha. The problems and the countermeasures in food production in Heilongjiang [J]. Research of Agricultural Modernization. 2012(4):411-414

[5] Lou Sha, Liu Huiping, Zhang Dehua. Comparative study on grain production and farmers' income coordination in Heilongjiang [J]. Research of Agricultural Modernization. 2013, Vol.34 (6):654-658

[6] Wang Peigang. Analysis on game path benefit subjects in current land expropriation [J]. Issues in Agricultural Economy, 2007(10):34-40

[7] Zhang Dehua. Study on influential factors and countermeasures of farmers' income in Heilongjiang [D]. Harbin: Northeast Agricultural University, 2013

[8] Cao Yukun, Chen Jiancheng, Chen Lirong. Game analysis on subject behaviors and policies in state-owned forest tenure reform in Yichun [J]. Issues in Agricultural Economy, 2010(5):89-95

[9] Liu Hongyuan, Chen Yinan. Analysis on rural land circulation and the sustainable development of farmers' land income [J] Rural Economy, 2014(12):10-14

[10]Chen Wensheng. Multi objective transformation of agricultural development in China under the restriction of resource and environment [J] Rural Economy, 2014 (12):3-9 